\title{
MICROGRAVITATIONAL NEUROGONIOMETRY AS A NOVEL MEASUREMENT TOOL FOR THE COMPLEX MORPHOFUNCTIONAL, MORPHOBIOCHEMICAL AND MORPHOPHYSIOLOGICAL STUDIES OF THE NEURON BIOPHYSICAL STATE IN SPACE CONDITIONS FOR EXPERIMENTS ON BIOSATELLITES
}

\author{
Oleg V. Gradov, Eugeny D. Adamovich
}

Institute for Energy Problems of Chemical Physics, Russian Academy of Sciences, Moscow, Russia

\author{
O.V. Gradov
}

38/2 Leninsky prospekt, Moscow, Russia 119334

E-mail: gradov@ center.chph.ras.ru, gradoff@bioinformatics.ru

\begin{abstract}
The effect of weightlessness / microgravity on the characteristics of the charge transfer across the neuron membrane is well known in space biology and medicine. In the absence of any gradients determining the growth directions of the neurites the neuron has a spherical shape characterized by the minimal surface. From the standpoint of functional morphology, it seems reasonable to design a system for a simultaneous monitoring of the electrobiophysical / electrophysiological and neuromorphological state of the brain neuronal structure, nervous tissue culture or the living slices directly in the microgravity / weightlessness conditions during the space flight. We have earlier developed a five-axis robotic positioning system for measurements on the living slices and tissue cultures, which demonstrated the dependence of the certain structure morphogenesis on its orientation in the gravitational field and external fields, as well as its correlation with the directed electrophysiological activity. The above system can be easily adapted to the astrophysical microgravity conditions.
\end{abstract}

Keywords: microgravitation, minimal surfaces, orbital station, biosatellites, spherical surfaces 


\section{Background}

The effect of weightlessness / microgravity on the characteristics of the charge transfer across the neuron membrane is well known in space biology and medicine (Wallace, 1995). In some cases this leads to the disorders in the neuron morphogenesis and the neurites' orientation due to the lack of the native forces which normally affect the neuron morphogenesis, resulting in disorientation in the gravitational field and significant changes in the normal diffusion and biorheological parameters (Sanderson, 1990; Crestini, 2004; Horn, 2006; Ranjan, 2014). In the absence of any gradients (Baier, 1992; Tessier-Lavigne, 1992; Baier, 1995; Bravo, 1997; Goodhill, 1998; Rosentreter, 1998; Legg, 2003; Davis, 2003; Goodhill, 2004; Flanagan, 2006; Suter, 2007; Thivierge, 2007; Caviness, 2009; Sundararaghavan, 2009; Millet, 2010; Martínez-Morales, 2011; Snyder, 2011; Keenan, 2012; Charvet, 2014; Kim, 2015) determining the growth directions and morphogenesis of the neurites the neuron has a spherical (Sala, 1990) shape characterized by the minimal surface (Sabitov, 1967) in homogeneous spaces (Van, 1989). Thus, in this case there is a topological transition since in the natural conditions of the orientated growth the tubular shape is the most probable one from the physical principles (Borisovich, 1997; Klyachin, 1997).

The authors have found and examined a series of slides in the collection of the former Brain Research Institute (Brain neuronal structure laboratory). According to the private communications which refer to the morphometric papers (Belichenko, 1988, 1989, 1991) describing the results obtained on the biomaterials from the biosatellite "Kosmos-1667" ("Bion-7"), the prolonged flight causes a partial involution of the neurites and spines leading to the pseudo-spherical neuron shape (see also clippings from contemporary works in the Figure 1).
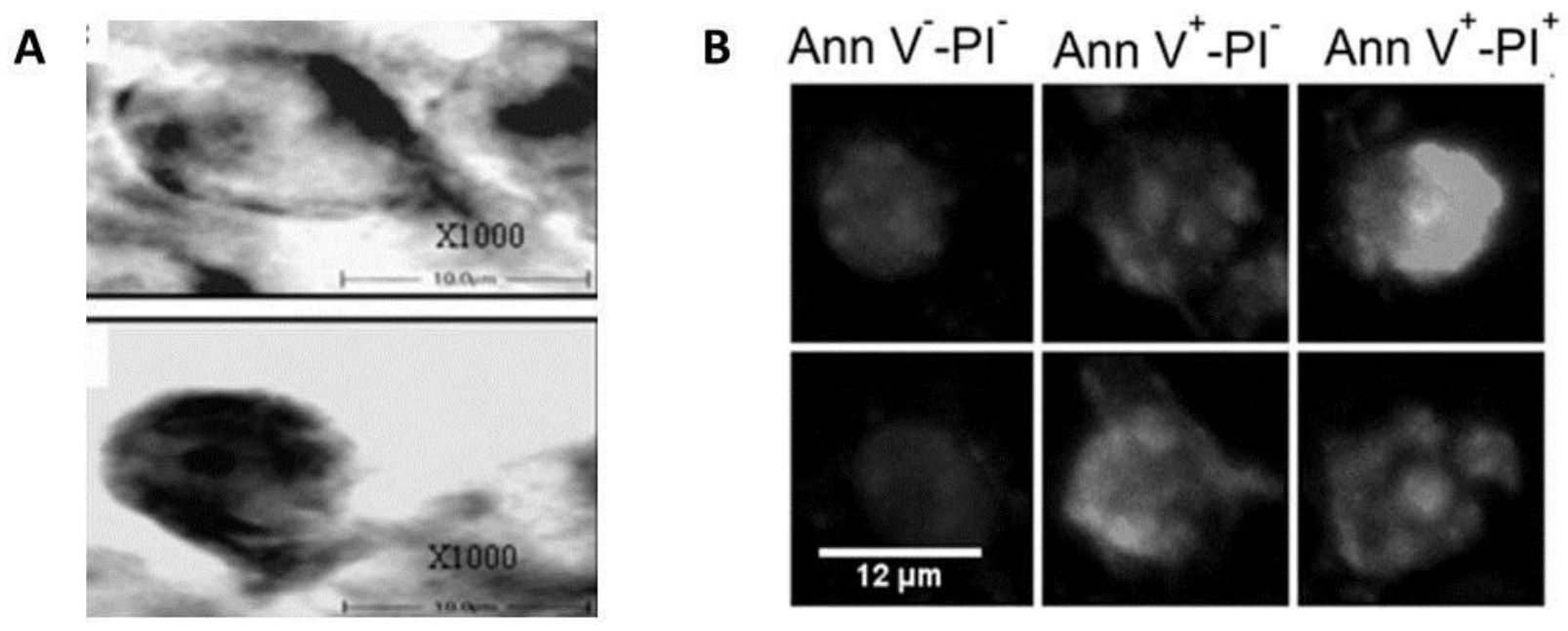

Figure 1. Some typical pseudo-spherical neuron shapes from microgravitational conditions: A adapted from (Ranjan, 2014); B - adapted from (Pani, 2013). Copy from the convolute archive of E.D. Adamovic.

\section{General Principles}

From the standpoint of functional morphology and a morphophysiological trend in the multivariate data analysis in situ, it seems reasonable to design a system for a simultaneous monitoring of the electrobiophysical / electrophysiological and neuromorphological state of the brain neuronal structure, nervous tissue culture or the living slices directly in the microgravity / weightlessness conditions during the space flight. We have earlier developed a five-axis robotic positioning system for measurements on the living slices and tissue cultures (Notchenko, 2013; Gradov, 2014; Gradov, 2014a; Oganessian, 2014), which demonstrated the dependence of the 
certain structure morphogenesis on its orientation in the external fields, as well as its correlation with the directed electrophysiological activity. The above system can be easily adapted to the weightlessness conditions.

We have already performed a calculation and design of the culture box - lab-on-a-chip - and a vital electrophysiological system for stereotactic positioning, which allow to study the coupled (morphofunctional / morphophysiological) changes in the electrophysiological activity modes and in the morphological / morphometric parameters of the neuronal structures (both in vivo or in situ, as well as in vitro on the living slices or tissue cultures) in the space flight conditions, as well as in natural conditions and under centrifugation.

Our preliminary data about neurogoniometry has been reported at the conference (see Figure 2) and the detailed publication of the technical documentation will also appear soon.
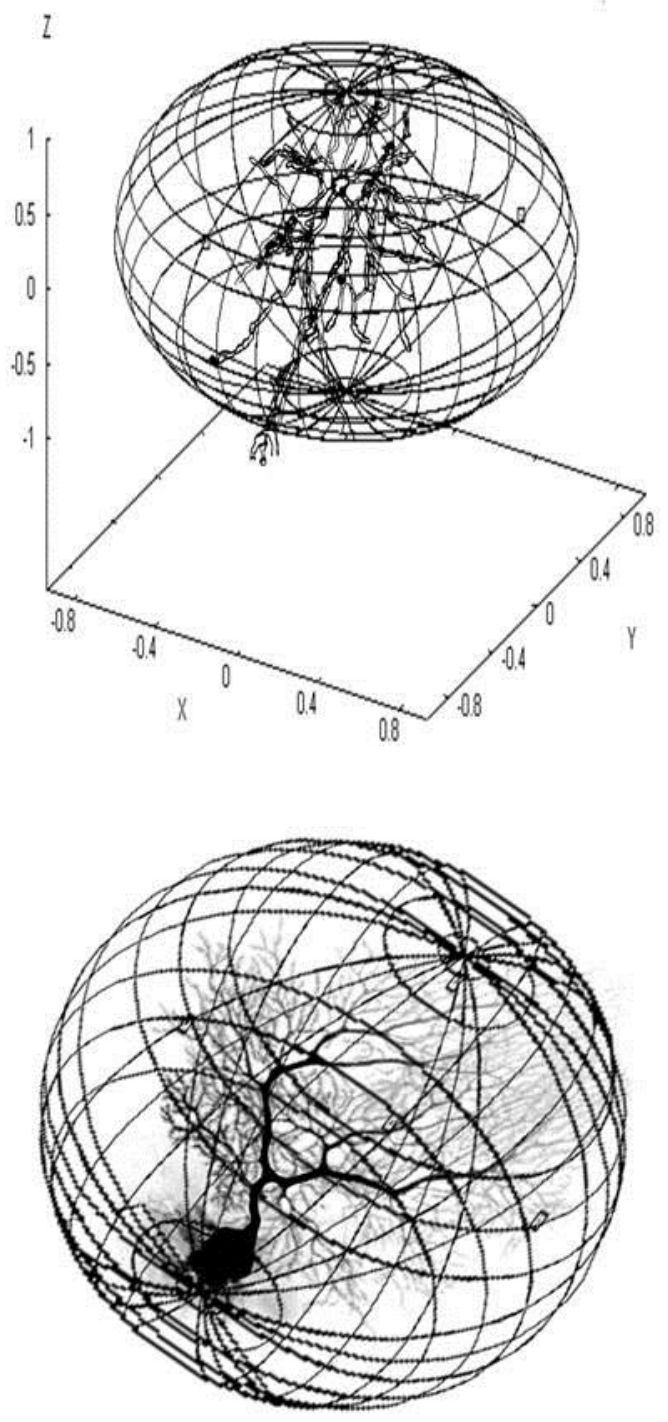

Figure 2. A scheme of neurogoniometry in spherical coordinates (from our conference paper and poster in the "International Symposium on Functional Neuroimaging - 2012" (Notchenko and Gradov, 2012)).

\section{References}

1. Baier H, Bonhoeffer F. Axon guidance by gradients of a target-derived component. Science 1992, 255(5043): 472-475. 
2. Bayer SA, Wills KV, Triarhou LC, Ghetti B. Time of neuron origin and gradients of neurogenesis in midbrain dopaminergic neurons in the mouse. Exp Brain Res 1995, 105(2):191199.

3. Belichenko PV. Quantitative analysis of dendritic spines of pyramidal neurons in layer V of the sensomotor cortex of rats exposed on the "Kosmos-1667" biosatellite. Bull Exp Biol Med 1988, 105(6):876-878.

4. Belichenko PV, Leontovich TA. Morphometry of giant multipolar neurons of the brain-stem reticular formation of rats carried on board the biosatellite "Kosmos 1667". Bull Exp Biol Med 1989, 107(5):714-717.

5. Belichenko PV, Krasnov IB. State of the dendritic spines of pyramidal neurons in layer V of the rat sensomotor cortex after 14-day space flight. Bull Exp Biol Med 1991, 112(5):1659-1660.

6. Borisovich AYu. Bifurcation of a capillary minimal surface in a weak gravitational field. Mathematics 1997, 188(3):341-370.

7. Bravo H, Inzunza O, Fernández V, Sanhueza M. Distribution of NADPH-d positive neurons during postnatal development of the rat somatosensory cortex correlates with gradients of neurogenesis and development. Neurosci Lett 1997, 234(23):103-106.

8. Caviness VS, Nowakowski RS, Bhide PG. Neocortical neurogenesis: morphogenetic gradients and beyond. Trends Neurosci 2009, 32(8):443-450.

9. Charvet CJ, Finlay BL. Evo-devo and the primate isocortex: the central organizing role of intrinsic gradients ofneurogenesis. Brain Behav Evol 2014, 84(2):81-92.

10. Crestini A, Zona C, Sebastiani P, Pieri M, Caracciolo V, Malvezzi-Campeggi L, Confaloni A, Di Loreto S. Effects of simulated microgravity on the development and maturation of dissociated cortical neurons. In Vitro Cell Dev Biol Anim 2004, 40(5-6):159-165.

11. Davis RL. Gradients of neurotrophins, ion channels, and tuning in the cochlea. Neuroscientist 2003, 9(5):311-316.

12. Flanagan JG. Neural map specification by gradients. Curr Opin Neurobiol 2006, 16(1):59-

66.

13. Goodhill GJ, Baier H. Axon guidance: stretching gradients to the limit. Neur Comput 1998, 10(3):521-527.

14. Goodhill GJ, Gu M, Urbac JS. Predicting axonal response to molecular gradients with a computational model of filopodial dynamics. Neur Comput 2004, 16(11):2221-2243.

15. Gradov OV, Notchenko AV, Oganessian VA. Microrefractometric and goniometric tomography based on multiaxis robotized Feodorov stage hybridized with pushintegrator and integrating Andine platform controled by stepper motors based on modified Harvard architecure microcontroller and CAMAC modules. In Proceedings of the 3rd International Conference "Practical microtomography", Saint Petersburg, 2014:41-44.

16. Gradov OV, Notchenko AV, Oganessian VA. Mechanotronic Neurogoniometry For in vivo $\&$ in situ Measurements on Neuroblast Cultures, Neurosphere-Like Stem Cell Clusters, Embryonic Brain Tissues \& Living Brain Slices. In Proceedings of the Skoltech Biomed Conference "Towards Therapies of the Future”, Moscow, 26-28 May, 2014a. DOI:10.13140/2.1.2616.1281.

17. Horn E, Böser S, Membre H, Dournon C, Husson D, Gualandris-Parisot L. Morphometric investigations of sensory vestibular structures in tadpoles (Xenopus laevis) after a spaceflight: implications for microgravity-induced alterations of the vestibuloocular reflex. Protoplasma 2006, 229(2-4):193-203.

18 Keenan TM, Grinager JR, Procak AA, Svendsen CN. In vitro localization of human neural stem cell neurogenesis by engineered FGF-2 gradients. Integr Biol 2012, 4(12):1522-1531.

19. Kim SE, Harker EC, De Leon AC, Advincula RC, Pokorski JK. Coextruded, Aligned, and Gradient-Modified Poly(e-caprolactone) Fibers as Platforms for Neural Growth. Biomacromolecules 2015, 16(3):860-867.

20. Klyachin VA. New examples of tubular minimal surfaces of arbitrary codimension. Math Notes 1997, 62(1):129-131. 
21. Legg AT, O'Connor TP. Gradients and growth cone guidance of grasshopper neurons. $J$ Histochem Cytochem 2003, 51(4):445-454.

22. Martínez-Morales PL, Diez del Corral R, Olivera-Martínez I, Quiroga AC, Das RM, Barbas JA, Storey KG, Morales AV. FGF and retinoic acid activity gradients control the timing of neural crest cell emigration in the trunk. J Cell Biol 2011, 194(3):489-503.

23. Millet LJ, Stewart ME, Nuzzo RG, Gillette MU. Guiding neuron development with planar surface gradients of substrate cues deposited using microfluidic devices. Lab Chip 2010, 10(12):1525-1535.

24. Notchenko AV, Gradov OV. 3D Neurogoniometry as a Novel Analytical Visualization for the Confocal Laser Scanning Microscopy [in Russian]; URL: http://psyjournals.ru/files/53746/Simposium_Neuroimaging_2012_new_Notchenko2.pdf

25. Notchenko AV, Gradov OV. A Five-Axis Arm-Manipulator Laser System and Algorithm for Digital Processing of Output Data for Recording and Morpho-Topological Identification of Cells and Tissue Structures. Visualization, Image Processing and Computation in Biomedicine 2013, 2:DOI:10.1615/VisualizImageProcComputatBiomed.2013005967.

26. Oganessian V, Notchenko A, Gradov O. Mechanotronic Neurogoniometer for in vivo and in situ Measurements on Living Brain Slices and Operating with a Stereotactic Apparatus. In Proceedings of the X Russian-German Conference on Biomedical Engineering, Saint Petersburg, 2014. DOI: 10.13140/2.1.2255.6809.

27. Pani G, Samari N, Quintens R, de Saint-Georges L, Meloni MA, Baatout S, Van Oostveldt $\mathrm{P}$, Benotmane MA. Morphological and Physiological Changes in Mature In Vitro Neuronal Networks towards Exposure to Short-, Middle- or Long-Term Simulated Microgravity. PLoS One 2013, 8(9):e73857. DOI:10.1371/journal.pone.0073857.

28. Ranjan A, Behari J, Mallick BN. Cytomorphometric Changes in Hippocampal CA1 Neurons Exposed to Simulated Microgravity Using Rats as Model. Front Neurol 2014, 5:77. DOI:10.3389/fneur.2014.00077.

29. Rosentreter SM, Davenport RW, Löschinger J, Huf J, Jung J, Bonhoeffer F. Response of retinal ganglion cell axons to striped linear gradients of repellent guidance molecules. $J$ Neurobiol 1998, 37(4):541-562.

30. Sabitov IK. Minimal surface as a diagram of sphere rotations. Math notes ASUSSR 1967, 2(6):881-887.

31. Sala F, Hernández-Cruz A. Calcium diffusion modeling in a spherical neuron. Relevance of buffering properties. Biophys J 1990, 57(2):313-324.

32. Sanderson KJ, Weller WL. Gradients of neurogenesis in possum neocortex. Brain Res Dev Brain Res 1990, 55(2):269-274.

33. Snyder JS, Ramchand P, Rabbett S, Radik R, Wojtowicz JM, Cameron A. Septo-temporal gradients of neurogenesis and activity in 13-month-old rats. Neurobiol Aging 2011, 32(6):11491156.

34. Sundararaghavan HG, Monteiro GA, Firestein B, Shreiber DI. Neurite growth in 3D collagen gels with gradients of mechanical properties. Biotechnol Bioeng 2009, 102(2):623-643.

35. Suter B, Nowakowski RS, Bhide PG, Caviness VS. Navigating neocortical neurogenesis and neuronal specification: a positional information system encoded by neurogenetic gradients. $J$ Neurosci 2007, 27(40):10777-10784.

36. Tessier-Lavigne M. Axon guidance by molecular gradients. Curr Opin Neurobiol 1992, 2(1):60-65.

37. Thivierge JP, Balaban E. Getting into shape: optimal ligand gradients for axonal guidance. Biosystems 2007, 90(1):61-77.

38. Van LV. Minimal surfaces in homogeneous spaces. Math of the USSR-IZV 1989, 32(2):413.

39. Wallace R. Microgravity and Charge Transfer in the Neuronal Membrane: Implications for Computational Neurobiology. In Proceedings of the LS\&SM Conference, USA, 1995: AIAA-951053; NASA-CR-205364. 